\title{
Repositórios Virtuais da Legislação Brasileira: o caso da Educação Indígena
}

\section{Virtual Repositories of Brazilian Legislation: the Case of Indigenous Education}

\author{
Jefferson Virgilio ${ }^{1}$ \\ ${ }^{1}$ Instituto de Ciências Sociais - Universidade de Lisboa, Lisboa, Portugal
}

Autor para correspondência/Mail to: Jefferson Virgilio, jv@ia.edu.pt

Copyright (c) 2017 Virgilio. Todo o conteúdo da Revista (incluindo-se instruções, política editorial emodelos) está sob uma licença Creative Commons AtribuiçãoNãoComercial-Compartilhalgual 3.0 Não Adaptada. Ao serem publicados por esta Revista, os artigos são de livre uso em ambientes educacionais, de pesquisa e não comerciais, com atribuição de autoria obrigatória. Mais informações em http://revistas.ufpr.br/atoz/about/submissions\#tcopyrightNotice.

\begin{abstract}
Resumo
Introdução: O presente texto apresenta os principais repositórios de materiais digitais sobre a legislação brasileira. É restrita a busca e a apresentação para os repositórios institucionais que são mantidos pelo Estado brasileiro.

Método: Apresenta-se a pesquisa realizada nestes repositórios virtuais visando recuperar os conteúdos de materiais que foram identificados como de difícil ou restrito acesso em momentos prévios à digitalização destes e sua disponibilização posterior em ambiente on-line. A pesquisa foi direcionada, especificamente, à legislação envolvendo a catequização e a educação indígena no Brasil.

Resultados: Reflete sobre os impactos positivos posteriores à disponibilização gratuita e em ambiente on-line destes materiais e pela plena possibilidade de realização de pesquisa em uma instituição de investigação estrangeira (em Portugal) sem a necessidade imediata de deslocamento para visita ou consulta aos arquivos físicos.

Conclusão: Finalmente, em menor grau, inclui breves reflexões sobre a possibilidade de consulta aos conteúdos de materiais antigos e raros sem colocar em risco a preservação e a integridade destes materiais.
\end{abstract}

Palavras-chave: Repositórios digitais. Repositórios institucionais. Legislação brasileira. Educação Indígena.

\begin{abstract}
Introduction: The present text presents the main repositories of digital materials on Brazilian legislation. The search and presentation is restricted for the institutional repositories maintained by the Brazilian State.

Method: The research carried out in these virtual repositories is carried out in order to recover the contents of materials that were identified as difficult or with restricted access in moments prior to the digitization of these and their later online availability. The research was specifically directed at the legislation involving indigenous catechization and indigenous education in Brazil.

Results: It reflects on the positive impacts after the free and online availability of these materials and the possibility of conducting research even at $a$ foreign research institution (in Portugal) without the immediate need to visit or consult the physical archives.

Conclusions: Finally, to a lesser extent, it includes brief reflections on the possibility of consulting the contents of old and rare materials without endangering the preservation and integrity of these materials.
\end{abstract}

Keywords: Digital repositories. Institutional repositories. Brazilian legislation. Indigenous education.

\section{INTRODUÇÃO}

O presente artigo apresenta uma relação dos repositórios online institucionais brasileiros que foram encontrados em uma primeira fase da pesquisa realizada para escrita de uma tese de doutorado. Em um segundo momento apresenta a metodologia de busca por legislação nestes repositórios, ilustrando a respectiva para um tema especifico, que é a educação indígena. Para testar a funcionalidade das ferramentas de busca dos repositórios utilizou-se uma lista de leis e decretos, que regulam ou norteiam a legislação envolvendo a educação indígena no Brasil.

A quantidade de referências acadêmicas incluídas no texto do artigo é reduzida, sendo intencional, e visa manter o conteúdo do artigo mais acessível. Em sentido próximo, na medida do possível, a apresentação da proposta pode ser mais descritiva do que analítica, visando permitir a replicação da proposta, com ou sem adaptações por partes terceiras. Um dos objetivos da tese de doutorado que originou a pesquisa era tornar mais acessível para as populações indígenas as discussões que são realizadas sobre as mesmas. Neste sentido, academicismos exagerados e ornamentos estéticos na apresentação dos resultados são intencionalmente evitados e reduzidos. A proposta de valorização de repositórios institucionais online caminha em vias próximas, ao incentivar a consulta e utilização destes repositórios e de suas fontes.

A pesquisa foi desenvolvida como a primeira parte de uma investigação de doutorado. Em um primeiro momento desta pesquisa foi necessário mapear repositórios de leis nacionais, que foram estabelecidas desde o império português em território brasileiro, até a atualidade sobre a educação indígena. Ainda que seja possível dissertar sobre a acessibilidade de documentos produzidos entre os séculos XVI e XIX sobre a educação indígena no Brasil, a maior parte destes materiais não está transcrito, estando apenas digitalizado. Muitos dos documentos produzidos após este período, ainda mantém limitada acessibilidade física, pelo próprio estado de conservação ou mesmo pela fragilidade ou quantidade de cópias conhecidas destes documentos. A visualização de versões 
digitalizadas ou transcritas de documentos foi considerada uma opção adequada desde o inicio da pesquisa. Um segundo fator considerado relevante, foi pela pesquisa ser iniciada em território estrangeiro (Lisboa, Portugal) ao longo de quase doze meses e, neste sentido, o acesso físico e direto à documentação sobre legislação nacional disponibilizado em bibliotecas, acervos ou arquivos físicos estava bastante limitada, valorizando ainda mais consultas aos documentos em formatos digitais.

\section{PROCEDIMENTOS METODOLÓGICOS E RESULTADOS}

Neste sentido, iniciou-se uma busca por repositórios online, utilizando como norteadores os textos de leis que já eram conhecidos. A segunda parte da pesquisa, que não será tratada neste artigo, envolveu a consulta pormenorizada e de longa duração em cada um destes repositórios, visando encontrar leis antigas que regulassem a catequese, o ensino e a educação indígena, para compreender o desenvolvimento desta área de atuação nos últimos séculos.

A fim de identificar parte dos repositórios que mantinham cópias completas de trechos de leis disponíveis online, foi utilizado um buscador simples online e funções específicas destes, que sumarizam e filtram os resultados. Por uma questão de acessibilidade, optou-se pelo buscador Google ${ }^{1}$, e neste, pela utilização da função de busca por trechos incluídos entre aspas duplas. Ao incluir um texto entre aspas duplas, as centenas de milhões de resultados que frequentemente são recuperadas em uma busca no Google são reduzidas para apenas aqueles resultados que possuem exatamente o trecho procurado. A metodologia aplicada é derivada do modelo exaustivamente desenvolvido e testado em uma pesquisa realizada entre 2014 e 2016 . A pesquisa que serviu como modelo foi desenvolvida para identificar o conjunto total de portadores de um diploma específico em Portugal através da combinação de filtros inteligentes e tabulação de dados obtidos online, sendo necessárias algumas adaptações para o propósito deste material.

Para o presente material, de maneira ilustrativa, optou-se inicialmente por incluir o texto completo do artigo $19^{\circ}$ do decreto que criou o Serviço de Proteção aos Índios (Brasil, 1910) entre aspas duplas no buscador Google, onde obtemos apenas cinco resultados. Os três primeiros resultados são o repositório do planalto central ${ }^{2}$, da câmara de deputados ${ }^{3}$, e do senado federal ${ }^{4}$, respectivamente. Os dois resultados finais são repositórios gerais de documentos de texto na internet que são mantidos por pessoas físicas ou jurídicas. Ao longo da pesquisa (2015 e 2017), foram realizadas consultas similares com outros 37 trechos de artigos de diferentes leis e decretos publicadas entre 1890 e 2016. Estes testes não são descritos ou incluídos neste material por uma questão de espaço. Os trechos de texto foram obtidos aleatoriamente entre uma lista de artigos construída no início da pesquisa.

Com exceção de trechos de textos oriundos da Constituição Federal de 1988, os resultados obtidos variaram de três a doze ocorrências no buscador Google. Também foram observadas algumas características comuns em todos os resultados obtidos. Essas características podem ser sintetizadas entre os itens a seguir: a) Quanto mais extenso for o trecho incluído entre aspas duplas, menor a quantidade de resultados obtidos; b) Quanto mais antiga for a lei, menor a quantidade de resultados obtidos; c) Alguns trechos de texto podem ser idênticos em leis de períodos distintos, gerando múltiplos resultados; d) Os três repositórios institucionais identificados aparecem em primeiras posições em todas as buscas realizadas; e) Trechos específicos dos textos de artigos da constituição de 1988 apresentam uma grande quantidade de monografias e artigos científicos entre os resultados. Esta situação ocorre, mas é rara, em trechos dos textos de outras constituições; f) Se houver reescrita ou adaptação do conteúdo textual de leis do final do século XIX e início do século XX para o português "moderno", a quantidade de resultados pode alterar substancialmente para um valor superior, com o sacrifício de alguns repositórios institucionais, que não aparecem em todos os resultados.

O repositório institucional e online do planalto central possui uma organização mais vasta da legislação além dos seus limites do que os repositórios da câmara e do senado. A função principal do portal remete à busca, que pode ser simples ou avançada. Em testes realizados com os termos ensino, educação, catequese, escola, letramento, letras e formação, além de variações diversas nas grafias destes termos, foram identificados e encontrados todos os documentos conhecidos sobre estes termos. A mesma situação ocorreu na busca por trechos específicos do conteúdo destas leis, ou mesmo pelos seus títulos. Apresentam uma quantidade de resultados substancialmente inferior aos dois outros repositórios consultados.

O repositório institucional da câmara de deputados possui uma organização menos detalhada da legislação que o repositório anterior. A função principal também remete à busca, e permite vários filtros adicionais, que não estão disponíveis no repositório do planalto central. Em testes realizados com os mesmos termos do teste anterior foram identificados e encontrados todos os textos que eram conhecidos. Situação idêntica ocorreu na busca por trechos específicos do conteúdo destas leis, ou mesmo pelos seus títulos. A quantidade de resultados

\footnotetext{
${ }^{1}$ Acesso online disponível em http://www.google.com

${ }^{2}$ Acesso online disponível em http://www4.planalto.gov.br/legislacao

${ }^{3}$ Acesso online disponível em http://www2.camara.leg.br/atividade-legislativa/legislacao

${ }^{4}$ Acesso online disponível em http://www25.senado.leg.br/web/atividade/legislacao
} 
atinge facilmente os milhares ou as centenas de milhares, tornando o uso da busca avançada praticamente uma obrigatoriedade para filtrar ou direcionar os resultados.

O repositório institucional do senado federal possui uma organização similar ao repositório da câmara. A função principal também remete à busca, porém possui três sistemas de organização. Ao utilizar a busca rápida, o usuário é forçado a decidir o tipo de norma. É neste sentido uma busca considerada mais engessada. Em testes realizados com os termos do teste anterior, foram identificados todos os textos conhecidos. O mesmo ocorreu na busca por trechos específicos do conteúdo destas leis, ou mesmo pelos seus títulos. Os resultados são distribuídos entre milhares de páginas, tornando o uso da pesquisa avançada ou da definição do tipo de norma, saídas quase obrigatórias.

Todos os repositórios possuem opção para apresentação das leis em modo atualizado (com emendas, vetos, alterações, etc.) ou com o texto de origem. Estas opções são especialmente úteis para pesquisas que analisem, por exemplo, a evolução do texto de determinada lei ou norma, como o Estatuto do Índio (Brasil, 1973), que recebem inúmeras alterações ao longo de décadas de existência. O modo como o texto das leis é apresentado permite não apenas acelerada forma de consulta ao seu conteúdo pelas ferramentas de busca, como possibilidade de indexação por motores de busca, como o Google, como a cópia de trechos textuais com ou sem formatação incluída.

Para o período que compreende entre 1890 e 2016 não foram encontrados documentos que foram simplesmente digitalizados. Todos os documentos consultados contam com versões em transcrição completa. Compreende-se o esforço investido na digitalização de acervos e não é a proposta julgar ou criticar tentativas previas de digitalizações, mas sim ressaltar algumas das vantagens da transcrição de certas fontes.

As percepções mais atualizadas sobre repositórios institucionais disponíveis online e de modo gratuito, segundo Franco (p. 19, 2015, grifos removidos) sugerem que:

Os repositórios surgiram com o propósito de preservação da memória e visibilidade institucional, porém esses ambientes não precisam ser obrigatoriamente científicos. Eles se iniciaram com esse objetivo, mas podem ser desenvolvidos com fins administrativos [...].

É possível incluir ainda os princípios de acesso à informação, seja na facilidade de disseminação, seja pelo reduzido custo de distribuição. Para o caso especifico da informação sobre legislação, a sua acessibilidade é garantida por lei desde 2011, via Lei de Acesso à Informação (Brasil, 2011), e está garantida pela Constituição desde 1988 (Brasil, 1988, ver art. 216, especialmente). Neste sentido, a proposta de pesquisa aqui realizada busca apenas ressaltar a importância e a facilidade de acesso aos repositórios institucionais legislativos atualmente em funcionamento, visando não apenas a sua divulgação, como a sua valorização e principalmente a sua continuidade e expansão. Ao permitir e incluir o conteúdo das legislações em ambiente online, e de modo gratuito, permite não apenas o amplo acesso da população nacional ao texto das leis, como de pesquisadores estrangeiros, seja para análise especifica, seja para análise comparativa, entre tantas outras possibilidades de uso do material online.

Há algum consenso sobre as vantagens da digitalização de obras raras, e este consenso pode ser recuperado, por exemplo em Greenhalgh (2011, p. 159-160), quando afirma que:

A principal linha de defesa para o processo de digitalização das obras raras trabalha com a preservação e disseminação desse material, com o argumento de que o processo beneficiará a longevidade dos livros, possibilitando o acesso ao conteúdo, sem a necessidade de manusear o original. Outro argumento favorável à digitalização de obras raras é o fato de ser um facilitador ao acesso e conhecimento dos livros, colocando-os disponíveis à consulta remota e ao alcance de buscadores on-line.

Sem grande dificuldade, estas percepções podem ser incluídas para materiais antigos ou de circulação reduzida, como é o caso de várias leis ou normas mais antigas, especialmente aquelas publicadas antes dos anos 80 . Estes materiais podem não ser exatamente raros, mas sim estarem apenas inacessíveis. Em um país de dimensões continentais como o Brasil, a distância física pode ser uma barreira ao acesso de inúmeros materiais para qualquer pessoa que não consiga aceder a determinadas capitais ou centros de acúmulo do saber e do conhecimento.

É neste sentido, que a legislação do final do século XIX e do início do século XX são compreendidas neste artigo. Materiais que, ainda que não possam ser classificados como obras raras, possuem reservada ou limitada capacidade de circulação e de acesso.

Os custos de deslocamento ou mesmo de empréstimo de exemplares físicos de livros, revistas ou jornais entre instituições de diferentes países (ou mesmo estados dentro do território brasileiro) podem ser impeditivos para a realização plena de uma pesquisa sobre determinado tema. Recupero aqui uma citação de Umberto Eco (2007, p. 71), onde a questão é enfatizada:

Geralmente, aceita-se o tema sem se saber se está em condições de aceder as fontes e é preciso saber: (1) onde elas se podem encontrar: (2) se são facilmente acessíveis; (3) se estou em condições de trabalhar com elas. 
Com efeito, posso aceitar imprudentemente uma tese sobre certos manuscritos de Joyce sem saber que se encontram na Universidade de Búfalo. ou sabendo muito bem que nunca poderei lá ir [...] poderei aceitar trabalhar num autor sem saber que os seus textos originais são raríssimos e que terei de viajar como um doído de biblioteca em biblioteca e de país em país.

Ou seja, a possibilidade de aceder ou não as fontes de consulta, pode efetivamente excluir a realização de determinada pesquisa por determinada pessoa ou instituição. Ao permitir o acesso online, remoto, gratuito e em plena qualidade de condições para qualquer pessoa com acesso à internet, uma das principais barreiras à produção do saber perde parte de sua base de sustentação.

\section{CONCLUSÕES}

Conclui-se que é fundamental a manutenção dos repositórios online de leis, pois além de cumprirem completamente com as suas funções, permitem o acesso alargado, ágil, e com reduzida burocracia ao seu conteúdo para quaisquer partes que estejam interessadas.

Salienta-se que para a pesquisa que originou este artigo, a classificação e a organização do conjunto de leis, além da facilidade de buscas com a utilização das palavras-chave, categorias ou mesmo em coleções especificas, que os repositórios online permitiram realizar, tornou possível mapear literalmente todo o conjunto de legislação nacional sobre educação indígena em um intervalo inferior a dois meses. Esta situação seria não apenas improvável temporalmente, como improvável em custos, se fossem necessários os deslocamentos à Brasília, Rio de Janeiro ou Salvador, onde são conhecidas cópias físicas de alguns dos documentos que foram consultados.

Para concluir, enfatiza-se a importância da disseminação da existência destes portais, sendo alinhada com politicas que garantam a maior e melhor acessibilidade possível. Percebe-se que há um real esforço do Estado brasileiro em manter estes repositórios funcionais e em plena acessibilidade.

Um segundo caminho que deve ser pensado e, idealmente iniciado, é o desenvolvimento de ações públicas que visem promover a universalização do acesso à internet, que ainda é limitado em diversas regiões do país, e inacessível a diversas instituições e pessoas. Ainda que boa parte das bibliotecas públicas, escolas e universidades ofereçam condições de acesso à internet aos seus usuários, esta situação está longe de ser plena ou acessível a toda população.

\section{AGRADECIMENTOS}

Agradeço as pareceristas da Associação de Arquivistas do Estado de Santa Catarina (AAESC) pelos comentários para uma versão prévia deste material que foi apresentado no XIII Encontro Catarinense de Arquivos. 


\section{REFERÊNCIAS}

Brasil. (1910). Decreto no 8.072, de 20 de junho de 1910.

Brasil. (1973). Lei no 6.001, de 19 de dezembro de 1973.

Brasil. (1988). Constituição da República Federativa do Brasil. Brasília.

Brasil. (2011). Lei no 12.527, de 18 de novembro de 2011.

Eco, U. (2007). Como se faz uma tese em ciências humanas. Lisboa: Editorial Presença.

Franco, I. d. M. (2015). Repositórios digitais institucionais: Um viés pela Lei de Acesso à Informação (Tese de doutorado, UFSCAR). Recuperado de https://repositorio.ufscar.br/ handle/ufscar/1144

Greenhalgh, R. D. (2011). Digitalização de obras raras: algumas considerações. Perspectivas em Ciência da Informação, 16 (3), 159-167. Recuperado de http://www.scielo.br/ pdf/pci/v16n3/10.pdf

Como citar este shortpaper (APA):

Virgilio, J. (2017). Repositórios Virtuais da Legislação Brasileira: o caso da Educação Indígena. AtoZ: novas práticas em informação e conhecimento, 6(2), $14-18$. Recuperado de: http://dx.doi.org/10.5380/atoz.v6i2 .57396 